$\begin{array}{ll}\text { Research Square } & \text { Preprints are preliminary reports that have not undergone peer review. } \\ \text { They should not be considered conclusive, used to inform clinical practice, } \\ \text { or referenced by the media as validated information. }\end{array}$

\title{
Knowledge About Obstetric Hazard Signs and Associated Factors Among Reproductive Age Women in South Eastern Zone of Tigray 2021. Cross Sectional Study
}

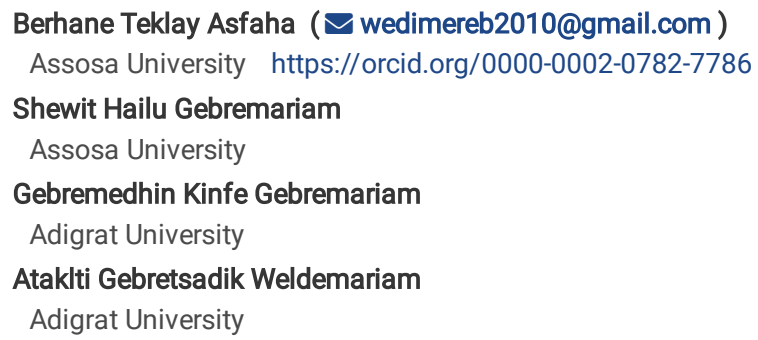

Research

Keywords: knowledge, obstetrics warning sign, reproduction, southeast, Tigray

Posted Date: January 4th, 2022

DOI: https://doi.org/10.21203/rs.3.rs-1210298/v1

License: (c) (7) This work is licensed under a Creative Commons Attribution 4.0 International License. Read Full License 


\section{Abstract}

Background: Pregnancy complications are the biggest health problem for women in developing countries. Around 295,000 women worldwide die each year from pregnancy-related causes, and $86 \%$ of this maternal mortality occurs in developing countries.

Objective: To assess knowledge about obstetric hazard signs among women of reproductive age living in the southeastern zone of the Tigray region, Ethiopia, 2021.

Methods: A community-based quantitative cross-sectional survey was conducted in the southeastern zone of Tigray. A multi-level random sampling technique was implemented to select the total participants from 410 women of reproductive age. Two districts were selected at random and from these districts 12 Kebels were selected at random and the calculated sample size (410) was proportionally assigned to each Kebele selected. The data was collected through face-to-face / interview with a structured questionnaire from January 20 to February 20, 2021, after it had been ensured that all ethical requirements were met. The collected data was entered into Epidata version 4.2 and then exported to SPSS version 20 for analysis. Descriptive statistics with frequency, percentage, table and graph as well as crosstabs were used to present the results. Bivariate and multivariable analyses were used to examine the relationship. Odds ratios with $95 \%$ confidence intervals and P-values $<0.05$ were used to determine the statistical association.

Result: Four hundred and ten women of childbearing age participated in the study, which resulted in a response rate of $100 \%$. Leakage of fluid per vagina was the most frequently cited obstetric hazard sign (61\%). Overall, one hundred and seventy-two (42\%) had a good knowledge of obstetric hazard signs. Educational status of the mother [AOR $(95 \% \mathrm{Cl}=2.7(1.189-6.24)$ ], place of birth [AOR $(95 \% \mathrm{Cl}=2.2(1.6-3.432)$ ] and with a history of ANC follow-up [AOR $(95 \% \mathrm{Cl}=2.4(1.13-5.6)]$ were found to be independent predictors of women's knowledge of the obstetric hazard sign.

Conclusion and recommendation: The mother's educational status, birth site and the history of ANC follow-up were independently related to the women's knowledge of obstetric hazard signs. Therefore, the provision of information, education and communication to women, families and the general community about obstetric hazard signs and related factors has been recommended.

\section{Plain English Summary}

Pregnancy-related complications are the number one health problem facing women in developing countries. Every year around 295,000 women worldwide die from pregnancy-related causes, and $86 \%$ of these maternal deaths occur in developing countries. Although significant progress has been made in all developing regions, the average annual percentage decrease in the world maternal mortality rate (MMR) has been $2.9 \%$; this means that the global MMR declined by an average of $2.9 \%$ annually between 2000 and 2017.410 respondents were asked about the obstetric danger sign and around $42 \%$ of them had a good knowledge of the obstetric danger sign. The main determining factors identified for knowledge of obstetric hazard signs were educational level (above secondary level), history of ANC follow-up, and place of birth (for the index child),

Conclusions; the majority of women of childbearing age in the study area had little knowledge of obstetric hazard signs. The educational status of the mothers, place of birth, and history of ANC follow-up were independently associated with women's knowledge of obstetric hazard signs. It is therefore recommended that information, education and communication be provided to women, families and the general public about obstetric hazard signs and related factors.

\section{Introduction}

Pregnancy-related complications are the most common health problem facing women in developing countries. Around 295,000 women worldwide die each year from pregnancy-related causes, and $86 \%$ of this maternal mortality occurs in developing countries. Although significant progress has been made in all developing regions, the average annual percentage decrease in the world maternal mortality rate (MMR) was $2.9 \%$; this means that the global MMR declined by an average of $2.9 \%$ every year between 2000 and 2017 (1). Approximately 500,000 women worldwide die each year from pregnancy complications, and unfortunately maternal aspects of maternal and child health have all too often been ranked second in the child survival revolution(2).

Developing countries account for $99 \%(284,000)$ of global maternal mortality, with most of them in sub-Saharan Africa $(162,000)$ and southern Asia $(83,000)$. These two regions accounted for $85 \%$ of global burden, with sub-Saharan Africa alone accounting for $56 \%$. The average maternal mortality rate in developing countries was 240 per 100,000 births in 2010, versus 16 per 100,000 in developed countries, due to inequalities in access to health services and highlighting the gap between rich and poor. Sub-Saharan Africa had the highest maternal death rate at 500 maternal deaths per 100,000 live births. According to a systematic analysis of progress towards achieving Millennium Development Goal 5, more than $50 \%$ of all maternal mortality in 2008 occurred in just six countries (India, Nigeria, Pakistan, Afghanistan, Ethiopia and the Democratic Republic of the Congo) (1).

The situation in Ethiopia is similar to that in many developing countries. In Ethiopia, maternal mortality and morbidity are among the highest in the world, and the current MMR estimate is 412 per 100,000 live births. That means that for every 1,000 births in Ethiopia there are about 4 maternal mortality(2).

Reducing maternal and neonatal mortality and morbidity have been identified as priority areas that need urgent attention from the health sector. Maternal morbidity and mortality could be prevented and significantly minimized if women and their families recognize obstetric signs of Hazard and seek immediate medical help (3).

The most common signs of Hazard during pregnancy are heavy vaginal bleeding, swollen hands / face, and blurred vision. Major signs of Hazard during labor and delivery include heavy vaginal bleeding, prolonged labor, convulsions, and placental retention. Signs of Hazard in the postpartum period include severe postpartum bleeding, postnatal unconsciousness, and fever. Bleeding remains the leading cause of maternal mortality, accounting for around a third of 
deaths. Many of the complications that lead to maternal death and contribute to prenatal death are unpredictable and can be both sudden and serious. The complications that lead to the death of the mother can occur without warning at any time during pregnancy and childbirth. Low awareness of the signs and symptoms of Hazard during pregnancy, labor, childbirth, and postpartum contributes to delays in finding and getting qualified care. Awareness of the Hazard signs of obstetric complications is the critical first step in accepting an appropriate and timely referral to obstetrics and neonatal care(4).

Knowledge of obstetric hazard signs and antenatal care are strategies aimed at improving the availability of quality care for low risk births and emergency obstetric care in complicated cases in low-income countries. More knowledge and awareness is essential to reduce delays in finding medical care and reaching a healthcare facility(5).

Communities and women should be empowered not only to recognize pregnancy related risks, but they must also have the means to react quickly and effectively once such problems arise(6). The national reproductive strategy of Ethiopia has placed emphasis on maternal and newborn health in order to reduce the high maternal and newborn mortality. The strategy focuses on the need to empower women, men, families and communities to identify pregnancyrelated risks and take responsibility for developing and implementing appropriate measures. One of the goals of the strategies is to ensure that $80 \%$ of families will recognize at least three signs of Hazard associated with pregnancy-related complications by 2010 in areas where the health promotion program is fully implemented (7).

Maternal mortality is the leading killer of adult women in many countries. The death of women during childbirth often means the death of the newborn, and both death and disability create emotional, social, and economic difficulties for the women's older children, their entire families, and even communities (8).

Every day 810 women die from preventable causes related to pregnancy and childbirth(9). Maternal mortality is preventable, skilled care before, during, and after the birth of a child and when women with complications are able to identify and receive appropriate emergency obstetric care that makes the difference between life and death (5). Maternal mortality has both direct and indirect causes. Approximately $73 \%$ of maternal mortality worldwide is caused by direct obstetric complications. The five most important global causes of maternal death are: severe bleeding (mostly postpartum bleeding), infections (also mostly shortly after delivery), unsafe induced abortions, hypertensive disorders during pregnancy (eclampsia) and obstacles to birth. Around $73 \%$ of maternal mortality rates worldwide are due to these causes. Bleeding alone accounts for a third of all maternal deaths in Africa, but many of these deaths are preventable. Serious postpartum bleeding can kill a healthy woman in two hours if left unattended. Obstetric fistulas resulting from the inhibition of labor are a long-term complication affecting up to two million women). Indirect causes such as malaria, diabetes, hepatitis, anemia, and other cardiovascular diseases made worse by pregnancy can also lead to the death of the mother (10).

Understanding the Hazard signs of obstetric complications is the critical first step in accepting an appropriate and timely referral to obstetrics and neonatal care. Raising women's awareness of the Hazards of pregnancy, childbirth and the puerperium improves mothers' attitudes to receiving medical attention and is key to safe motherhood (11).

If mothers fail to recognize the signs of Hazard during pregnancy, negative effects can occur on the mother, the unborn child or the pregnancy itself. Side effects include: maternal illness or death; B. Heavy bleeding can lead to anemia or the death of the mother, infection of the unborn child through prematurely torn mucous membranes when amniotic fluid leaks from the vagina. Failure to do so can lead to fetal or neonatal morbidity and mortality, premature termination of pregnancy due to vaginal bleeding. Maternal high blood pressure or fever 4 can lead to an increased number of deaths in newborns or premature babies who may eventually die from inadequate care facilities(12).

The death of a mother in childbirth denies her children their natural primary caregiver and significantly increases the risk that her child will die or not reach the age of 5 . Many children who survive without mothers also run the risk of being lost emotionally (13). Most maternal mortality is preventable as the health solutions to prevent or treat complications are known. All women need access to prenatal care, qualified care during childbirth and care and support in the weeks after the birth. It is especially important that all births are accompanied by qualified health care workers, as timely treatment and treatment can make the difference between life and death $(13,14)$.

According to the Ethiopian Demographic Health Survey 2016 , only $26 \%$ of deliveries are cared for in health facilities. In a country where the maternal mortality rate is 412 per 100,000 live births and the IMR 48/1000 and NMR 29/1000 live births are the highest in the world. In Ethiopia, since the introduction of Health Extension Workers (HEWs), there has been little information about the knowledge, attitude and practice of obstetric hazard signs during pregnancy, although the national reproductive strategy aims to raise awareness in the area where HEW. to be used to $80 \%$ (2).

A study conducted in the Tsegedie district showed that women's knowledge of obstetric hazard signs was low and was influenced by the neighborhood. Therefore, identified awareness deficits should be addressed by maternal and child health services by developing appropriate strategies, including the provision of targeted information, education and communication. Despite the great potential for knowledge, attitude, and practice of obstetric hazard signs to reduce maternal and newborn mortality, their status is not well known in most of sub-Saharan Africa, including Ethiopia(15). The aim of this study is therefore to close this gap by assessing the current state of knowledge about Hazard signs in mothers in the study area

\section{Methods}

\section{Study setting}

The regional state of Tigray is one of the nine regional states of Ethiopia that are located in northern Ethiopia. The capital of Tigray is Mekelle City, which is $781 \mathrm{~km}$ from Addis Ababa. The study area was in the south-eastern zone of the regional state of Tigray. It is bordered to the south by the South Zone, to the southeast by the Amhara region, to the northeast by the Central Zone, to the north by the Eastern Zone and to the east by the Afar region. The latitude and longitude of the administrative centers of the districts is Endrta (Quiha) with latitude and longitude of $1302837 \mathrm{~N}, 3903242 \mathrm{E}$ with an altitude of 2247

Page $3 / 11$ 
meters above sea level, DeguaTemben ( $\mathrm{H}$ / selam) latitude and longitude found $13039 \mathrm{~N} 39010 \mathrm{E}$ with an altitude of 2650 meters above sea level, H / wejerat (Adi Gudem) is located 13015 N $39031 \mathrm{E}$ with an altitude of 2100 meters above sea level and Samre is located $13^{0} 11 \quad \mathrm{~N} 39^{0} 12 \mathrm{E}$ with elevation of 1855 meters above sea level.

The estimated population according to the 2007 census conducted by the CSA is 392,142, of which 21,125 or $5.39 \%$ are urban residents (16). The zone has four woredas Saharti Samre, Hintalo Wejerat, D / Temben and Enderta with a total of 87 Kebeles, 23 of them in Saharti Samre, 23 in Hintalo Wejerat, 24 in Degua Temben and 17 in Enderta. It also includes seven primary hospitals, 25 health centers, and 83 health posts. The study will run from January 20 to February 20, 2021 in the southeastern zone of Tigray.

\section{Participants}

The study population selected women of childbearing age who lived in the southeastern zone of Tigray and who met the inclusion criteria. All women of childbearing potential who were mentally stable, those who were available at the time of data collection, women who were not seriously ill were included, while women of childbearing potential who are health professionals or health professionals were excluded.

\section{Sample size determination and sampling technique}

The required sample size will be determined using single population proportion formula with the following assumption: the proportion of knowledge on obstetric danger sign is $58.8 \%$ which was done in Tsegede district(15), with $95 \%$ confidence level and $5 \%$ degree of precision was assumed to compute the sample size. And then the final sample size was 410. A random sampling technique was used to select the total of 410 study participants, Hintalo Wejerat and DeguaTemben. From these four woredas, two woredas were selected by means of a simple random sample. Hintalo Wejerat and Enderta were selected accordingly. There are 23 Kebeles in Hintalo Wejerat and 17 Kebeles in Enderta Wereda with a total of 39 Kebeles. Six Kebeles were selected from 23 in Hintalo Wejerat and six Kebeles from 17 Kebeles in Enderta by means of a simple random sample. Maernet, Dedba, Arato and Meseret were selected by Enderta and Mesanu, Hiwane, M / Nebri, Hareko were included by H / Wejerat. The calculated sample size (410) was proportionally assigned to each selected Kebeles in both woredas. A list of women of childbearing age was obtained from HEWs. Individual units were then selected using a simple random sample to obtain the required data.

Study Variables

\section{Dependent Variable}

Dependent Variable:

Knowledge of obstetric hazard signs

Independent Variables

Socio-demographic factors (age, marital status, religion, women's education, occupation, age at marriage and residence). Obstetric Factors

$>$ Other factors (Source of information and distance to health institution).

\section{Definition of terms}

Hazard signs: Presence of a medical condition that increases the likelihood that a pregnant woman and / or her unborn child will die or be in poor health.

Knowledge: Knowledge of Obstetric Hazard Signs is the basic piece of information mothers must have about Obstetric Hazard Signs.

Knowledge: Knowledge of Obstetric Hazard Signs is the basic piece of information mothers must have about Obstetric Hazard Signs.

Good knowledge: refers to those participants who answer knowledge questions correctly and are above the mean.

\section{Poor knowledge}

refers to those participants who answer knowledge questions correctly and are below the mean

\section{Data collection tools and techniques}

For data collection, a structured face-to-face questionnaire in English is adapted after reviewing various literatures and modified depending on the local situation and research goal. It was originally developed in English and translated into Amharic by a native Amharic person. And it has been translated back into English by another person to maintain its consistency. The questionnaire included questions about socio-demographic characteristics, source of healthrelated information, history of contraceptive use, obstetrics, and questions about knowledge of obstetric hazard signs. Five qualified midwives and three health professionals at BSc level were recruited and trained as data collectors and supervisors. Eligible participants were approached and asked to voluntarily consent to participate in the study. After approval, a study number with a code for identification was assigned. Inclusion in the study was done by using the proportion of Kebeles and then selecting them at random until the required sample size was achieved using a structured face-to-face questionnaire

\section{Data quality assurance and control}


The data collection instrument was checked in advance for correctness of the answers, language transparency, correctness of the data collection tools, estimation of the time required and the necessary adjustments based on this before the actual data collection. It was carried out one week before the actual survey period in five percent of the non-study participants who met the inclusion criteria. In addition, the data collectors were trained in data collection techniques for a day. The training also included the importance of explaining to study participants the potential use and purpose of the study before starting data collection. The maintenance of the confidentiality of the participants during the entire process of data collection was discussed and ensured during the training. The researcher was checked for completeness and consistency of the questionnaires completed by the data collectors to ensure the quality of the data and visited the data collectors as often as possible to verify that he was collecting the data appropriately. The researcher also evaluated the data during the data analysis phase to check the completeness of the data collected.

\section{Data Processing and Analysis}

After data collection, Epi data version 4.2 was used for input and then exported to SPSS version 20 for analysis. A binary logistic regression model was used to determine the factors associated with an obstetric fistula. Those variables that were clinically important and had a $\mathrm{P}<0.25$ in the bivariate analysis were the candidate variables for the final multivariable binary logistic regression model. The raw and adjusted measures of the effect-odds ratio were determined to be $95 \% \mathrm{Cl}$ and $\mathrm{P}<0.05$ was used to declare statistical significance. The goodness of fit of the final model was assessed using the Hosmer and Lemeshow goodness test and multicollinearity was checked. Finally, the result was presented using tables, figures and texts.

\section{Results}

\subsection{Socio-demographic Character of the study participants}

The response rate of the study participants was $100 \%$. The mean age and standard deviation of the study participants were 36.51 and 9.712 (ranging from 15 49) years, respectively. Most of the study participants (37.1\%) were found at the age of $>=45$ years and with regard to religion, most of them $75.1 \%$ (308/410) were Orthodox. In terms of educational status, about $57.1 \%$ (234/410) of the participants were illiterate. Regarding marital status, the majority (69.8\%) of the participants was married (Table 1). 
Table 1

Socio-demographic characteristics of respondents among reproductive age women in south eastern zone of Tigray, Ethiopia 2021, $(\mathrm{N}=410)$

\begin{tabular}{|c|c|c|c|}
\hline Variable & Category & Frequency & Percentage (\%) \\
\hline \multirow[t]{5}{*}{ Age } & $15-24$ & 82 & 20 \\
\hline & $25-34$ & 92 & 22.4 \\
\hline & $35-44$ & 84 & 20.5 \\
\hline & $>=45$ & 152 & 37.1 \\
\hline & Total & 410 & 100 \\
\hline \multirow[t]{3}{*}{ Religion } & Orthodox & 308 & 75.1 \\
\hline & Muslim & 102 & 24.9 \\
\hline & Total & 410 & 100 \\
\hline \multirow[t]{4}{*}{ Marital status } & Single & 108 & 26.3 \\
\hline & Married & 286 & 69.8 \\
\hline & Widowed & 16 & 3.9 \\
\hline & Total & 410 & 100 \\
\hline \multirow[t]{3}{*}{ Ethnicity } & Tigraweyty & 378 & 92.2 \\
\hline & Afar & 32 & 7.8 \\
\hline & Total & 410 & 100 \\
\hline \multirow[t]{6}{*}{ Educational status } & Illiterate & 234 & 57.1 \\
\hline & Read and write & 42 & 10.2 \\
\hline & Elementary school & 32 & 7.8 \\
\hline & Secondary school & 44 & 10.7 \\
\hline & Diploma and above & 58 & 14.1 \\
\hline & Total & 410 & 100 \\
\hline \multirow[t]{5}{*}{ Occupation } & House wife & 254 & 62 \\
\hline & Government employed & 72 & 17.6 \\
\hline & Student & 66 & 16.1 \\
\hline & Merchant & 18 & 4.4 \\
\hline & Total & 410 & 100 \\
\hline \multirow[t]{6}{*}{ Income } & $<=500$ & 246 & 60 \\
\hline & $501-1000$ & 76 & 18.5 \\
\hline & $1001-1500$ & 24 & 5.9 \\
\hline & $1501-2000$ & 30 & 7.3 \\
\hline & $>=2001$ & 34 & 8.3 \\
\hline & Total & 410 & 100 \\
\hline \multirow[t]{5}{*}{ Husband occupation(N=310) } & Farmer & 144 & 46.45 \\
\hline & Government employed & 44 & 14.19 \\
\hline & Private employed & 58 & 18.7 \\
\hline & Merchant & 64 & 20.65 \\
\hline & Total & 310 & 100 \\
\hline \multirow[t]{3}{*}{ Residence } & Rural & 340 & 83 \\
\hline & Urban & 70 & 17 \\
\hline & Total & 410 & 100 \\
\hline
\end{tabular}


Most of the subjects (67.8\%) had a history of pregnancy, and most of them had a pregnancy rate of $52.9 \%(148 / 410)$ more than four times that of the frequency of pregnancy. For a history of intrauterine fetal death, the majority of $92.1 \%(258 / 280)$ of participants did not. Approximately the time it takes to reach the health facility, the majority of $75.6 \%$ (310/410) of participants take $>=30$ minutes to reach the health facility. Through the information source, $76.8 \%$ received information about obstetric hazard signs from health workers (Table 2).

Table 2

Past Obstetric characteristics of mothers aged 15-49 years in south eastern Zone, Tigray region, Northwest Ethiopia, 2021

\begin{tabular}{|c|c|c|c|}
\hline Variable & Category & Frequency & Percentage (\%) \\
\hline \multirow[t]{2}{*}{ Ever been pregnant } & Yes & 278 & 67.8 \\
\hline & NO & 132 & 32.2 \\
\hline \multirow[t]{4}{*}{ Frequency of pregnancy $(\mathrm{N}=280)$} & One times & 110 & 39.3 \\
\hline & 2-4 times & 22 & 7.9 \\
\hline & Above 4 times & 148 & 52.9 \\
\hline & Total & 280 & 100 \\
\hline \multirow[t]{4}{*}{ Age during first pregnancy $(\mathrm{N}=280)$} & $<22$ & 138 & 49.3 \\
\hline & $22-29$ & 30 & 10.7 \\
\hline & $>=30$ & 112 & 40 \\
\hline & Total & 280 & 100 \\
\hline \multirow[t]{3}{*}{ Hx of ANC follow up } & Yes & 222 & 80 \\
\hline & No & 56 & 20 \\
\hline & Total & 278 & 100 \\
\hline \multirow[t]{2}{*}{ Site of delivery } & Health institution & 216 & 78 \\
\hline & Home & 52 & 32 \\
\hline \multirow[t]{4}{*}{ Total No of birth(N=280) } & One & 32 & 11.4 \\
\hline & Two & 114 & 40.7 \\
\hline & Above two & 134 & 47.9 \\
\hline & Total & 280 & 100 \\
\hline \multirow[t]{3}{*}{ History of IUFD(N=280) } & Yes & 22 & 7.9 \\
\hline & No & 258 & 92.1 \\
\hline & Total & 280 & 100 \\
\hline \multirow[t]{2}{*}{ Time taken to reach Heath institution } & $<30$ minutes & 100 & 24.4 \\
\hline & $>=30$ minutes & 310 & 75.6 \\
\hline \multirow[t]{2}{*}{ Source of information about obstetric Hazard sign } & Health worker & 315 & 76.8 \\
\hline & Media & 95 & 23.2 \\
\hline
\end{tabular}

\section{Knowledge about obstetric Hazard signs}

Respondents' knowledge of delivery services was assessed using questions about signs of Hazard associated with pregnancy and childbirth. When the participants were asked to name an obstetric hazard sign, the most common spontaneous hazard signs were 242 ( $59 \%$ ) fluid leakage per vagina, 244 ( $59.5 \%$ ) body swelling, 187 (45.6\%) absence or decrease in FHB., Prolonged labor by 234 (57\%), excessive vaginal bleeding by 245 (60\%), and placental retention by 166 (40.5\%). Altogether, one hundred and seventy-two (42\%) of the respondents gave the mean value of the obstetric Hazard signs mentioned above, two hundred and thirty-eight (58\%) named the lower mean value of the obstetric Hazard signs [Table 3] 
Table 3

Knowledge of the obstetric Hazard signs among mothers aged 15-49 years in South eastern, Tigray region, North Ethiopia, June 2021 $(n=410)$.

\begin{tabular}{|c|c|c|c|}
\hline Variable & Category & Frequency & Percentage \\
\hline \multirow[t]{3}{*}{ PrenatalVaginal bleeding } & Yes & 245 & 60 \\
\hline & No & 165 & 40 \\
\hline & Total & 410 & 100 \\
\hline \multirow[t]{3}{*}{ Leakage of fluid } & Yes & 242 & 59 \\
\hline & No & 168 & 41 \\
\hline & Total & 410 & 100 \\
\hline \multirow[t]{3}{*}{ Bod swelling } & Yes & 244 & 59.5 \\
\hline & No & 166 & 40.5 \\
\hline & Total & 410 & 100 \\
\hline \multirow[t]{3}{*}{ Persistent head ach and visual disturbance } & Yes & 207 & 50.5 \\
\hline & No & 203 & 49.5 \\
\hline & Total & 410 & 100 \\
\hline \multirow[t]{2}{*}{ Prolonged labour } & Yes & 234 & 57 \\
\hline & No & 176 & 43 \\
\hline \multirow[t]{3}{*}{ Absence or decrease FHB } & Yes & 187 & 45.6 \\
\hline & No & 223 & 54.4 \\
\hline & Total & 410 & 100 \\
\hline \multirow[t]{3}{*}{ Retained placenta } & Yes & 166 & 40.5 \\
\hline & No & 244 & 59.5 \\
\hline & Total & 410 & 100 \\
\hline \multirow[t]{3}{*}{ Excessive Post-partum vx bleeding } & Yes & 245 & 60 \\
\hline & No & 165 & 40 \\
\hline & Total & 410 & 100 \\
\hline
\end{tabular}

\section{Associated factors of Knowledge on obstetric Hazard sign}

Binary logistic regression was performed to identify significant factors with knowledge of obstetric hazard signs, then those factors with a p-value less than 0.25 were included in the multivariable analysis during the bivariate analysis. The variables that were significantly associated in the bivariate analysis were educational level, marital status, history of ANC follow-up, age during first pregnancy, total number of births, total number of live births, place of birth, and frequency of pregnancy. The multivariable binary logistic regression analysis showed the following result. Educational level, place of birth, and course of ANC follow-up were independently associated with knowledge of obstetric hazard signs. Women of childbearing age who had a diploma and above were 2.7 times more likely to have a good knowledge of obstetric hazard signs compared to women of childbearing age who were illiterate [AOR $(95 \% \mathrm{Cl}=2.7(1.189-6,24)]$ ). Women with a history of ANC follow-ups were 2.4 times more likely to have a good knowledge of obstetric hazard signs compared to their colleagues [AOR $(95 \% \mathrm{Cl}=2.4(1.13-5.6)) .2 .2$ times more likely good knowledge of obstetric hazard signs compared to those without [AOR $(95 \% \mathrm{Cl}=2.4(1.3-5.3)](\mathrm{Table} 4\}$ 
Table 4

Associated factors of knowledge on obstetric Hazard sign among reproductive age women in south eastern zone

\begin{tabular}{|c|c|c|c|c|c|}
\hline \multirow[t]{2}{*}{ Variable } & \multirow[t]{2}{*}{ Category } & \multicolumn{2}{|c|}{ Knowledge } & \multirow[t]{2}{*}{$\operatorname{COR}(95 \% \mathrm{Cl})$} & \multirow[t]{2}{*}{$\mathrm{AOR}(95 \% \mathrm{Cl})$} \\
\hline & & Good & Poor & & \\
\hline \multirow[t]{5}{*}{ Educational level } & Illiterate & 76 & 158 & 1 & 1 \\
\hline & Read and write & 16 & 26 & $1.27(0.69-3.12)$ & $1.2(0.53-3.23)$ \\
\hline & Primary education & 3 & 29 & $0.23(0.12-1.5)$ & $0.86(.295-1.334)$ \\
\hline & 2dry Education & 23 & 21 & $7.8(3.028-13.49)^{\star \star}$ & $2.2(.877-5.48)$ \\
\hline & Diploma and above & 50 & 8 & $13(9.475-19.119)^{\star \star}$ & 2.7(1.189-6.24)* \\
\hline \multirow[t]{2}{*}{ Marital status } & Married & 133 & 153 & $1.82(1.22-4.3)^{\star}$ & $2.2(0.342-3.432)$ \\
\hline & Single & 35 & 73 & 1 & 1 \\
\hline \multirow[t]{3}{*}{ Frequency of pregnancy } & One & 41 & 69 & 1 & 1 \\
\hline & Two-four & 12 & 10 & $2(1.08-5.76)^{\star}$ & $1.23(0.87-4.32)$ \\
\hline & Above Four & 81 & 69 & $1.98(1.12-3.35)^{\star}$ & $3.3(1.12-4.8)^{\star \star}$ \\
\hline \multirow[t]{2}{*}{ History of ANC follow up } & YES & 120 & 102 & $2.12(1.3-4.8)^{\star \star}$ & $2.4(1.13-5.6)$ ** \\
\hline & NO & 20 & 36 & 1 & 1 \\
\hline \multirow[t]{3}{*}{ Age during first pregnancy } & $<22$ years & 41 & 97 & 1 & 1 \\
\hline & $22-29$ years & 20 & 10 & $4.73(0.56-7.2)$ & $2(0.89-5.543)$ \\
\hline & $>=30$ years & 73 & 39 & 4.43(0.793-7.98) & $3.21(0.896-8.43)$ \\
\hline \multirow[t]{2}{*}{ Frequency of birth } & $1-4$ & 39 & 69 & $8.6(5.57-13.293)^{\star \star}$ & $1.6(.761-3.201)$ \\
\hline & $>4$ & 95 & 77 & 1 & 1 \\
\hline \multirow[t]{3}{*}{ Total live birth } & 1 & 14 & 18 & 1 & 1 \\
\hline & 2 & 35 & 79 & $0.57(0.12-2.42)$ & $0.3(0.1-5)$ \\
\hline & $>2$ & 85 & 49 & $2.25(1.32-7.7)^{\star}$ & $1.5(0.13-6.2)$ \\
\hline \multirow[t]{2}{*}{ Site of delivery } & Institution & 216 & 78 & $1.7(1.02-5.23)^{\star}$ & $2.2(1.3-5.3) \star \star$ \\
\hline & Home & 52 & 32 & 1 & 1 \\
\hline
\end{tabular}

\section{Discussion}

This cross-sectional community-based study identified factors influencing knowledge of obstetric hazard signs among women of childbearing age in the southeastern zone of Tigray. According to this study, about $42 \%$ (37-48.4\%) of the participants had a good knowledge of obstetric hazard signs which was higher than the study conducted in Tanzania and Zambia $(17,18)$ that was $25.2 \%$ and $29 \%$, respectively. The difference could be that due to different years of study, knowledge of obstetric hazard signs is expected to improve from time to time due to better access and better use of the health information provided. But compared to studies in Madagascar and Egypt, it was lower $(19,20)$ that was $51.9 \%$ and $79.6 \%$, respectively. This difference could be due to differences in the study setting, this study was community based but the previous studies were institutional, they can access health information provided by health professionals. This study shows that there is a significant correlation between women's knowledge of obstetric hazard signs and their level of education; Women with a diploma and a higher level of education had 2.7 times [AOR $(95 \% \mathrm{Cl}=2.7(1.189-6.24)$ ] rather good knowledge of obstetric hazard signs compared to women of reproductive age who had no education / illiterate This is because educated women were more likely to use institutional delivery services than uneducated women, which in some cases might be better informed about

obstetric complications and obstetric hazard signs Study in Tsegedie district, western Tigray region(15). Those who gave birth in a health facility were 2.2 times more likely to have [AOR $(95 \% \mathrm{Cl}=2.2(1.3-5.3)]$ good knowledge of obstetric hazard signs compared to those who did had a history of home birth. This can be explained by the fact that the increased awareness among women who have had an inpatient delivery in the past is related to health education by health care professionals. The other strong predictor of women's knowledge about the obstetric hazard sign was a place where the ANC has a history of being followed. The likelihood of being knowledgeable was 2.4 times $(95 \% \mathrm{Cl}=2.4$ (1.13-5.6)] higher if the mothers had a history of ANC follow-up, which can be explained by the fact that awareness increased in women who had a history of ANC follow-up to the knowledge of women who had an ANC follow-up A history of may be related to the health-related information and training given by health professionals on each visit, especially those who have had complications related to their pregnancy. And it is in line with the study carried out in Madagascar(19). 
The main obstetric hazard signs assessed included leakage of fluid per vagina, body swelling, absence or decrease in FHB, prolonged labor, excessive postpartum vaginal bleeding, and placental debris. In line with the findings from Tanzania, Madagascar and the Thegedie district(19, 21, 22) This study showed that more than half $(60 \%)$ of the study participants named vaginal bleeding as a sign of Hazard. This study was supported by a study carried out in Tanzania (21)

\section{Conclusions And Recommendation}

The results of the study indicate that the majority of women of childbearing age in the study area had little knowledge of obstetric hazard signs. In addition, the mother's educational status, place of birth, and history of ANC follow-ups were independently linked to women's knowledge of obstetric hazard signs. Therefore, the provision of information, education and communication to women, families and the general community about obstetric hazard signs and related factors has been recommended.

\section{Abbreviations}

ANC - prenatal care, AOR - Adjusted Odds Ratio, Cl - Confidence Interval, COR - Crude Odds Ratio, CSA - Central Statistical Authority, DHS - Demographic and Health Survey, EDHS - Ethiopian Demographic and Health Survey, HEW - Health Extension Worker, IEC - Information, Education and Communication, IMRInfant Mortality Rate, JHPIEGO- Johns Hopkins Program for International Education in Gynecology and Obstetrics, KAP- Knowledge, Attitude and Practice, MDG- Millennium Development Goal, MMR- Maternal Mortality Rate, MOH- Ministry of Health, NMR- Newborn Mortality Rate, SPSS -Statistical Package for Social Science, TBA -Traditional Obstetrician TV-Television, UNICEF -United Nations Children Fund, WHO -World Health Organization, ETB- Ethiopian Birr, IUFDIntrauterine Fetal Death.

\section{Declarations}

\section{Ethical consideration}

Before the actual data collection permission was obtained from Mekelle University, the Health Science College and the School of Nursing from the Tigray Health Bureau and then from the Health Bureaus of the Southeastern Zone, the study participants were explained the aim of the study. Data protection and confidentiality of the study participants were preserved through the use of study codes on data documents without identifiers on the study instruments other than serial numbers. In addition, study participants' involvement was based on their willingness.

\section{Consent for publication}

Not applicable

\section{Availability of data and materials}

The data sets used in the current study are available from the relevant author upon justified request.

\section{Computing interest}

The authors declare that they have no competing interests.

\section{Funding}

No fund had been given to conduct this study.

\section{Authors' contributions}

BT designed the study, performed statistical analysis and authored the paper. SH, GK and AG participated in the writing of papers. All authors contribute to the data analysis and have read and approved the final paper.

\section{Acknowledgments}

We would like to thank all study participants, the supervisors of the data collection and the data collectors for their worthy commitment and their participation in this study. We are also grateful to the managing authorities at all levels for helping us carry out these studies.

\section{References}

1. WHO, UNICEF, UNFPA WBG and the U, Division NP. MMR-maternal-deaths-and-LTR_MMEIG-trends_2000-2017-revised. 2017.

2. EDHS. FEDERAL DEMOCRATIC REPUBLIC OF ETHIOPIA Demographic and Health Survey. 2016. 1-59 p.

3. Kheamy D, Bardisi S. Knowledge and Factors Associated With Obstetric Danger Signs Among Pregnant Women in Al-Nawariah Primary Health Care Center, Makkah Al-Mukarramah, 2016, (a Cross-Sectional Study). Int J Adv Res. 2017;5(8):381-93.

4. Rashad W a, Essa RM. Women 's Awareness of Danger Signs of Obstetrics Complications. Science (80-) [Internet]. 2010;6(10):1299-306. Available from: http://www.americanscience.org 
5. Nyfløt L, Sitras V. Strategies to reduce global maternal mortality. Acta Obstet Gynecol Scand. 2018;97(7):639-40.

6. Prata N, Tavrow P, Upadhyay U. Women's empowerment related to pregnancy and childbirth: Introduction to special issue. BMC Pregnancy Childbirth. 2017;17(Suppl 2):1-6.

7. Democratic F, Of R, Reproductive N, Strategy H. FEDERAL DEMOCRATIC REPUBLIC OF ETHIOPIA MINISTRY OF HEALTH. 2015;(June 2005).

8. World Health Organization. Trends in Maternal Mortality: 1990 to 2013 Estimates by WHO, UNICEF, UNFPA. 2014;

9. The C, Transformative T. Every day 810 women die from preventable causes related to pregnancy and childbirth. :10-5.

10. Say L, Gemmill A, Moller A. Global Causes Of Maternal Death: A Who Systematic Analysis Global causes of maternal death: a WHO systematic analysis. 2014;(June).

11. Pembe AB, Urassa DP, Carlstedt A, Lindmark G, Nyström L, Darj E. Rural Tanzanian women's awareness of danger signs of obstetric complications. BMC Pregnancy Childbirth. 2009;9:1-8.

12. Geleto A, Chojenta C, Musa A, Loxton D. WOMEN's Knowledge of Obstetric Danger signs in Ethiopia (WOMEN's KODE):a systematic review and metaanalysis. Syst Rev. 2019;8(1):1-14.

13. In T, Mortality M. TRENDS IN MATERNAL MORTALITY: 2000 TO 2017. 2017.

14. Group WB. Trends in Maternal Mortality: 1990 to 2015. 2015;

15. Hailu D, Berhe H. Knowledge about obstetric danger signs and associated factors among mothers in Tsegedie district, Tigray region, Ethiopia 2013: Community based cross-sectional study. PLoS One [Internet]. 2014;9(2):0-7. Available from: https://doi.org/10.1371/journal.pone.0083459

16. Commission federal democratic repuplic of ethiopia population censucs. 4 Summary and Statistical Report of the 2007 Population and Housing Census Results. Popul size by age sex. 2007;

17. Nambala BS, Ngoma C. Knowledge and Perception of Women Towards Danger Signs in Pregnancy in Choma Rural District , Zambia. $2013 ; 40(2): 43-7$.

18. Bintabara D, Mpembeni RNM, Mohamed AA. Knowledge of obstetric danger signs among recently-delivered women in Chamwino district, Tanzania: a cross-sectional study. 2017;1-10. Available from: DOI 10.1186/s12884-017-1469-3

19. Salem A, Lacour O, Scaringella S, Herinianasolo J, Benski AC, Stancanelli G, et al. Cross-sectional survey of knowledge of obstetric danger signs among women in rural Madagascar. 2018;1-9. Available from: DOI 10.1186/s12884-018-1664-x

20. Gebrehiwot H, Bahta S, Haile N. Awareness of Danger Signs of Pregnancy and its Associated Factors among Pregnant Women who Visit ANC in Mekelle Public Hospitals. Am J Adv Drug Deliv [Internet]. 2014;2(2): 164-173. Available from:

http://www.academia.edu/6875011/Awareness_of_Danger_Signs_of_Pregnancy_and_its_Associated_Factors_among_Pregnant_Women_who_Visit_ANC_in_M

21. Mwilike B, Nalwadda G, Kagawa M, Malima K, Mselle L, Horiuchi S. Knowledge of danger signs during pregnancy and subsequent healthcare seeking actions among women in Urban Tanzania: A cross-sectional study. BMC Pregnancy Childbirth [Internet]. 2018;18(1):1-8. Available from: DOI 10.1186/s12884017-1628-6

22. Aborigo RA, Moyer CA, Gupta M, Adongo PB, Williams J, Hodgson A, et al. Obstetric danger signs and factors affecting health seeking behaviour among the Kassena-Nankani of Northern Ghana: a qualitative study. Afr J Reprod Health. 2014;18(3):78-86. 